\title{
Effect of a platelet activating factor antagonist, WEB 2086, on allergen induced asthmatic
}

\section{responses}

\author{
A Freitag, R M Watson, G Matsos, C Eastwood, P M O’Byrne
}

\begin{abstract}
Background-Platelet activating factor (PAF) has been implicated in the pathogenesis of airway hyperresponsiveness in asthma. The purpose of this study was to evaluate the effects of a selective PAF antagonist (WEB 2086), given in doses known to antagonise the effects of inhaled PAF in human subjects, on allergen induced early and late asthmatic responses and on airway hyperresponsiveness.
\end{abstract}

Methods-Eight atopic, mildly asthmatic subjects were studied during a screening period and two treatment periods. During the screening period subjects inhaled an allergen to which they were known to be sensitised and the response was measured as the fall in the forced expired volume in one second $\left(F E V_{1}\right)$ to show the presence of early $(0-1$ h) and late (3-7 h) asthmatic responses. On another day the subjects inhaled allergen diluent. During the treatment periods subjects inhaled allergen after one week's pretreatment with WEB 2086 (100 mg three times a day) or placebo administered in a randomised, double blind, crossover fashion. Histamine airway responsiveness was measured 24 hours before and 24 hours after allergen and the results were expressed as the provocative concentration causing a $20 \%$ fall in $F_{1} V_{1}\left(\mathbf{P C}_{20}\right)$.

Results-The maximal early asthmatic response after allergen with placebo treatment was $18.4 \%$ (SE $4 \cdot 4 \%$ ) and with WEB $208618 \cdot 9 \%(4 \cdot 4 \%)$. The maximal late response with placebo treatment was $21 \cdot 7 \%(5 \cdot 3 \%)$ and with WEB $208621 \cdot 2 \%$ $(3.0 \%)$. The log difference (before and after allergen) in histamine $\mathbf{P C}_{20}$ was $\mathbf{0 . 3 5}$ $(0.06)$ after placebo treatment and 0.30 (0.1) after WEB 2086.

Conclusions-These results indicate that one week of treatment with an orally administered PAF antagonist (WEB 2086) does not attenuate allergen induced early or late responses or airway hyperresponsiveness.

(Thorax 1993;48:594-598)

Inhalation of environmental allergens is an important cause of exacerbations of asthma.
In the laboratory allergen inhalation tests are a useful tool for investigating the pathogenesis of allergen induced asthma. Allergen inhalation causes narrowing of the airways, in sensitised subjects, usually within 15 minutes. This early asthmatic response resolves within two to three hours. In half or more adult subjects a late bronchoconstrictor response, which begins three to four hours after allergen inhalation, also occurs. ${ }^{1}$ The late asthmatic response is more prolonged than the early response and is associated with airway hyperresponsiveness to bronchoconstrictor stimuli such as histamine or methacholine, ${ }^{2}$ and this can last for days or weeks after exposure to allergen. ${ }^{3}$

The early asthmatic response occurs because of the release of bronchoconstrictor mediators such as histamine, ${ }^{4}$ the sulphidopeptide leukotrienes, ${ }^{56}$ and thromboxane $\mathrm{A}_{2}{ }^{78}$ The late response and subsequent airway hyperresponsiveness is associated with an inflammatory response, shown by an influx of inflammatory cells such as eosinophils, ${ }^{9}$ into the airways. However, the precise role of the inflammatory cells in causing late asthmatic responses is not yet known.

Platelet activating factor (PAF) is a potent proinflammatory mediator derived from the metabolism of phospholipids from cell membranes and released from a variety of cells, including basophils, macrophages, neutrophils, and eosinophils. ${ }^{10}$ It has various actions, which include the recruitment and activation of inflammatory cells, particularly eosinophils and neutrophils. ${ }^{11}$ Inhaled PAF also causes bronchoconstriction and airway hyperresponsiveness in normal subjects ${ }^{1213}$ and is released into the plasma after allergen inhalation in mildly asthmatic subjects. ${ }^{14}$ For these reasons it is thought to be an important mediator in the development of allergen induced late asthmatic responses and airway hyperresponsiveness. Indeed, one of its potent and selective antagonists, WEB $2086,{ }^{15}$ inhibits allergen induced late responses in allergic sheep. ${ }^{16}$ In human subjects WEB 2086 prevents the bronchoconstriction induced by $\mathrm{PAF},{ }^{17}$ and in human bronchi in vitro it prevents the histamine hyperresponsiveness induced by the factor. ${ }^{18}$ In this study we evaluated whether WEB 2086 inhibits allergen induced asthmatic responses and airway hyperresponsiveness in atopic subjects with mild asthma. 


\section{Methods}

SUBJECTS

Ten subjects were originally entered into the study. Eight subjects completed all parts of the study and were included in the statistical analysis. All subjects were studied in the asthma research laboratories of McMaster University Medical Centre. The subjects were chosen because they had a history of mild, stable, asthma and allergy to an environmental allergen (table). The subjects were taking inhaled $\beta_{2}$ agonists only infrequently, and no subject had taken any other asthma drugs for more than one year. Subjects had not been currently exposed to allergens to which they were sensitised (with the exception of the housedust mite) and had had no exacerbations of asthma for at least four weeks. The baseline forced expiratory volume in one second $\left(\mathrm{FEV}_{1}\right)$ was more than $75 \%$ of predicted normal values ${ }^{19}$ in all subjects on all study days. The study was approved by the hospital ethics committees, and each subject gave written informed consent before beginning the study. Two subjects were entered but did not complete the study. One subject did not have a late asthmatic response during the screening period and was not entered into the randomisation periods. A second subject entered the randomisation periods and received placebo treatment during the first period, but the histamine airway responsiveness did not return to baseline values before starting the second randomisation period and the subject was withdrawn from the study before receiving any treatment with WEB 2086.

\section{STUDY DESIGN}

Subjects attended the laboratory during three study periods; a screening period and two treatment periods. The screening period consisted of four study days. On the first day the characteristics of subjects were documented and informed consent was obtained. On the second day a diluent inhalation test with saline was performed and the $\mathrm{FEV}_{1}$ measured over seven hours (see section on diluent inhalation tests). At the completion of the test a skin prick test titration with the relevant allergen was performed, to obtain the allergen end point as previously described, ${ }^{20}$ and a histamine inhalation test performed. On the third day an allergen inhalation test was performed, and on the fourth day, the day after

Clinical characteristics of subjects in study

\begin{tabular}{llllll}
\hline & & \multicolumn{3}{l}{ Baseline } & \\
\cline { 3 - 5 } Case no & Age (years) & Sex & $F E V_{1}(\%$ predicted) & $P C_{20}(\mathrm{mg} / \mathrm{ml})$ & Allergen \\
\hline 1 & 24 & $\mathrm{M}$ & 76 & $0 \cdot 23$ & D farinae \\
2 & 38 & $\mathrm{M}$ & 76 & $2 \cdot 12$ & D fariane \\
3 & 37 & $\mathrm{M}$ & 91 & $0 \cdot 13$ & D farinae \\
4 & 24 & $\mathrm{M}$ & 80 & $4 \cdot 17$ & Ragweed \\
5 & 20 & $\mathrm{M}$ & 76 & $0 \cdot 85$ & Ragweed \\
6 & 23 & $\mathrm{M}$ & 103 & 1.90 & D farinae \\
7 & 33 & $\mathrm{M}$ & 93 & $1 \cdot 26$ & Ragweed \\
8 & 38 & $\mathrm{~F}$ & 113 & $\mathbf{5 \cdot 2 1}$ & D farinae \\
\hline
\end{tabular}

allergen inhalation, a histamine inhalation test was performed to document the change in airway responsiveness after allergen inhalation.

The two treatment periods consisted of eight study days each. During the treatment periods subjects were randomly allocated to receive either WEB $2086100 \mathrm{mg}$ or placebo administered orally three times daily for seven days before, on the day of, and on the day after allergen inhalation. The allergen inhalation tests were carried out one hour after a dose of treatment. A histamine inhalation test was performed the day before beginning the treatment, after six days of treatment, one day before the allergen inhalation, and the day after allergen inhalation. A blood sample was obtained just before the ingestion of the treatment on the allergen inhalation day for measurement of plasma WEB 2086 concentrations. The study was double blind, randomised, and with a crossover design.

The screening and the two treatment periods were separated by at least two weeks. The response to inhaled allergen was determined partly by the degree of airway responsiveness. Therefore, each study period was started only when histamine airway responsiveness had returned to within a single doubling concentration of the initial value during the screening period. Inhaled $\beta_{2}$ agonists were withheld for at least eight hours before either the histamine or the allergen inhalation tests.

\section{HISTAMINE INHALATION TESTS}

Histamine inhalation tests were carried out by the method of Cockcroft et al with a Wright's nebuliser (output: $0.13-0.15 \mathrm{ml} / \mathrm{min}$, mass median aerodynamic diameter of particles: $1.3 \mu \mathrm{m}) .{ }^{19}$ After nebulisation of phosphate buffered saline with $1.5 \%$ benzyl alcohol $(\mathrm{pH}$ $7 \cdot 4$ ) increasing doubling concentrations of histamine phosphate were inhaled until a $20 \%$ fall in $\mathrm{FEV}_{1}$ was obtained. Doseresponse curves were drawn on a semilogarithmic non-cumulative scale. The concentration causing a $20 \%$ fall in $\mathrm{FEV}_{1}$ $\left(\mathrm{PC}_{20}\right)$ was interpolated from the individual dose-response curves. $\mathrm{PC}_{20}$ was obtained in all subjects in this manner.

\section{ALLERGEN INHALATION TESTS}

Allergen inhalation tests were performed as previously described with a Wright nebuliser operated by oxygen at a pressure of $345 \mathrm{kPa}$ $\left(50 \mathrm{lbf} / \mathrm{in}^{2}\right)$ and at a flow rate sufficient to provide an output $0.13 \mathrm{ml} / \mathrm{min} .^{18}$ The nose was clipped and aerosols were inhaled through a mouthpiece during tidal breathing.

The starting concentration of allergen extract for inhalation was determined from a formula described by Cockcroft et al ${ }^{20}$ using the results from the skin prick test end point titration with the same extract and the histamine $\mathrm{PC}_{20}$ in the entry period. The starting concentration of allergen extract for inhalation was two doubling concentrations below that predicted to cause a $20 \%$ fall in $\mathrm{FEV}_{1}$.

Doubling concentrations of allergen were inhaled for two minutes and $\mathrm{FEV}_{1}$ measured 
10 minutes after each inhalation. If $\mathrm{FEV}_{1}$ fell by $10 \%$ or more measurements were repeated every 10 minutes until no further fall was observed. $\mathrm{FEV}_{1}$ was then measured at 20, 30, $45,60,90$, and 120 minutes and every hour until seven hours after allergen inhalation.

The allergen extracts were obtained from Miles/Hollister-Stier, Mississagua, Ontario. Extracts were stored at $-70^{\circ} \mathrm{C}$ and diluted for skin tests and allergen inhalation on the day they were to be used.

\section{DILUENT INHALATION TESTS}

Diluent inhalation tests were performed with a Wright nebuliser as described above. Subjects inhaled diluent (phosphate buffered saline with $1.5 \%$ benzyl alcohol) three times for two minutes and then $\mathrm{FEV}_{1}$ was measured as described in the previous section on allergen inhalation tests.

\section{MEASUREMENT OF PLASMA WEB 2086 CONCENTRATION}

Blood samples were collected as described in the section on the study design and the plasma was stored at $-70^{\circ} \mathrm{C}$ until analysis. WEB 2086 was analysed by using a titrated radioimmunoassay with a sensitivity for WEB 2086 in plasma of $0.1 \mathrm{ng} / \mathrm{ml}$ and negligible cross reactivity with its known metabolites $(<0 \cdot 1 \%)$.

\section{ANALYSIS}

The primary end point of the study was evaluation of the ability of pretreatment with WEB 2086 to inhibit allergen induced late asthmatic responses. The effect of WEB 2086 on histamine airway responsiveness, allergen induced early asthmatic responses, and allergen induced increases in histamine airway responsiveness were also compared with the effects of placebo.

All analyses of histamine $\mathrm{PC}_{20}$ were performed on $\log$ transformed data, with summary statistics being expressed as geometric means and $95 \%$ confidence intervals. All other summary statistics are expressed as arithmetic means with standard errors of the mean. The bronchoconstrictor responses during the early (up to one hour) and late (three to seven hours) asthmatic responses with saline, placebo, and WEB 2086 were compared using two way analysis of variance appropriate for repeated measures data.

Comparison of the log difference (the arithmetic ratio) of histamine $\mathrm{PC}_{20} 24$ hours before and 24 hours after allergen in both study periods is appropriate for assuming the effects of treatment on allergen induced airway hyperresponsiveness, a log difference of 0 signifying no change in airway responsiveness. Log transformed $\mathbf{P C}_{20}$ measurements are normally distributed; therefore, the effect of WEB 2086 and placebo on baseline histamine responsiveness and on the increases in histamine responsiveness after allergen were compared using two tailed Student's $t$ tests for paired observations. Statistical significance was accepted as $p<0.05$. The power of the study to detect a $50 \%$ inhibition of the late response (the primary end point) by WEB 2086 was evaluated retrospectively.

\section{Results}

Treatment with WEB 2086 did not significantly attenuate baseline lung function, allergen induced early and late asthmatic responses, baseline histamine airway responsiveness, or allergen induced increases in histamine airway responsiveness.

\section{BASELINE LUNG FUNCTION}

Treatment with WEB 2086 did not influence the baseline $\mathrm{FEV}_{1}$. During the screening period the mean baseline $\mathrm{FEV}_{1}$ was 3.771 (SE 0.37 1). The mean baseline $\mathrm{FEV}_{1}$ after seven days' treatment with placebo was $3.851(0.41$ 1) and after seven days' treatment with WEB $20863.711(0.451)(p>0.05)$.

\section{ALLERGEN INDUCED EARLY AND LATE RESPONSES}

During the screening period the mean maximal early fall in $\mathrm{FEV}_{1}$ during the first hour after allergen was $23.9 \%(2 \cdot 1 \%)$ and the mean maximal late fall in $\mathrm{FEV}_{1}$ between three and seven hours after allergen was $25.4 \%$ $(2 \cdot 5 \%)$. The mean maximal early fall in $\mathrm{FEV}_{1}$ after allergen during placebo treatment was $18 \cdot 4 \%(4 \cdot 4 \%)$ compared with $18.9 \%(4 \cdot 4 \%)$ after allergen during WEB 2086 treatment ( $p>0.05$ ) (fig 1). The mean maximal late fall in $\mathrm{FEV}_{1}$ after allergen during placebo treatment was $21 \cdot 7 \%(5 \cdot 3 \%)$ and during WEB 2086 treatment $21.2 \%(3.0 \%)(p>0.05)$ (fig 1). The power of the study to detect a $50 \%$ inhibition of the late asthmatic response (the primary end point in the study) by WEB 2086 was $83 \%$.

\section{ALLERGEN INDUCED HISTAMINE AIRWAY} HYPERRESPONSIVENESS

During the screening period the mean histamine $\mathrm{PC}_{20}$ was $1.42 \mathrm{mg} / \mathrm{ml}$ (95\% confidence

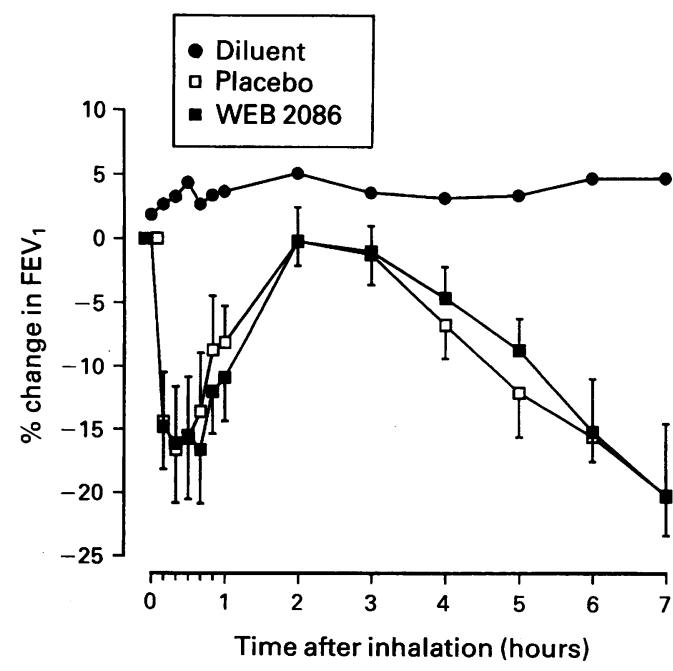

Figure 1 Mean (SE) fall in FEV, after inhaled diluent ( - ) and during the early and late asthmatic response after inhaled allergen after pretreatment with placebo ( $\square-\square)$ or WEB 2086 ( - ). WEB 2086 had no significant effect on the size of the early or late asthmatic responses. 
interval 1.00 to $3 \cdot 86) 24$ hours before allergen and $0.53 \mathrm{mg} / \mathrm{ml}(0.43$ to 1.65$) 24$ hours after allergen. Before placebo treatment mean histamine $\mathrm{PC}_{20}$ was $1.29 \mathrm{mg} / \mathrm{ml}(1.09$ to $4 \cdot 18)$ and before WEB $2086 \quad 1 \cdot 17 \mathrm{mg} / \mathrm{ml}$ (1.05 to 4.07). The mean histamine $\mathrm{PC}_{20} 24$ hours before allergen was $2.00 \mathrm{mg} / \mathrm{ml}(0 \cdot 78$ to 3.01$)$ during placebo treatment and 1.64 $\mathrm{mg} / \mathrm{ml}(0.99$ to 3.81$)$ during WEB 2086 treatment $(p>0.05)$. After allergen inhalation the mean histamine $\mathrm{PC}_{20}$ decreased to $0.90 \mathrm{mg} / \mathrm{ml}(0.27$ to 1.05$)$ during placebo treatment and to $0.82 \mathrm{mg} / \mathrm{ml}(0.29$ to 0.95$)$ during WEB 2086 treatment (fig 2). The mean $\log$ difference of the histamine $\mathrm{PC}_{20}$ before and after allergen was $0.35(0.06)$ during placebo treatment and $0.30(0.10)$ during WEB 2086 treatment ( $p>0.05$ ) (fig 2).

\section{PLASMA WEB 2086 CONCENTRATIONS}

Measurable plasma concentrations of WEB 2086 were obtained during WEB 2086 treatment in all subjects. The mean concentrations were $54.5(8 \cdot 1) \mathrm{ng} / \mathrm{ml}$ for the group, but WEB 2086 was undetectable $(<0 \cdot 10 \mathrm{ng} / \mathrm{ml})$ in all subjects during placebo treatment.

\section{Discussion}

We found that treatment for one week with WEB 2086 did not significantly alter baseline histamine airway responsiveness or inhibit the size of allergen induced asthmatic responses or allergen induced histamine airway hyperresponsiveness.

WEB 2086 is a selective and potent antagonist of the PAF receptor, with an $\mathrm{IC}_{50}$ for PAF induced platelet aggregation in humans of $0.17 \mu \mathrm{mol} / 1 .{ }^{15}$ WEB 2086 has been the most widely used antagonist to evaluate the role of PAF in experimental models of human disease, including allergen induced airway responses in sheep. ${ }^{16}$ A single oral dose of WEB 2086 (40 mg) abolishes the bronchoconstrictor effects of PAF $^{17}$ and the histamine

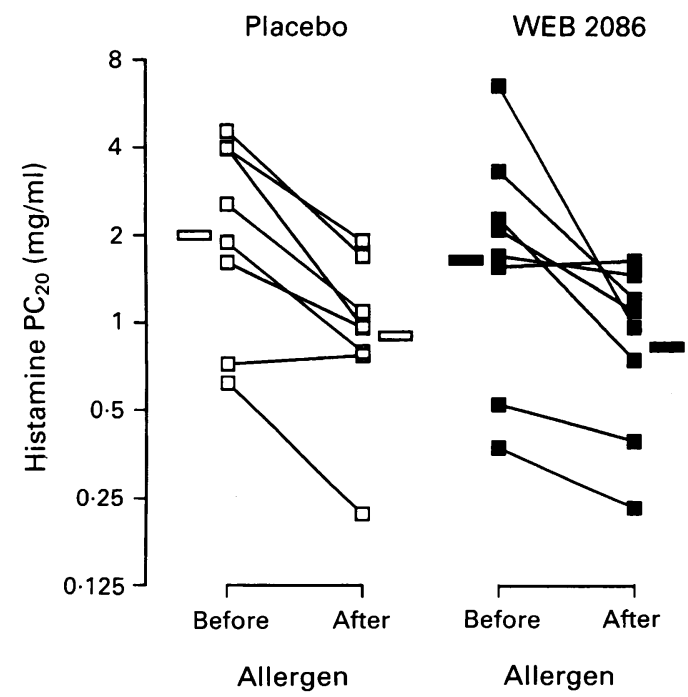

Figure 2 Airway responsiveness to inhaled histamine on the day before and after allergen inhalation during placebo and WEB 2086 pretreatment. Histamine airway

responsiveness increased 24 hours after allergen inhalation and was not inhibited by WEB 2086 pretreatment. hyperresponsiveness induced by the factor in human bronchi studied in vitro. ${ }^{18}$

WEB 2086 treatment did not significantly alter baseline airway calibre, as measured by the $\mathrm{FEV}_{1}$ or baseline histamine airway responsiveness before allergen. This suggests that PAF may not be an important mediator in controlling baseline airway function in subjects with mild asthma. In addition, WEB 2086 had no effect on allergen induced asthmatic responses. An important role for PAF in causing allergen induced dual responses was initially suggested by Basran et al who found that, when given intracutaneously, it caused a dual skin response in human subjects similar to that caused by intracutaneous allergen. ${ }^{22}$ In addition, inhaled PAF causes bronchoconstriction and airway hyperresponsiveness in non-asthmatic subjects. ${ }^{12}{ }^{13}$ Lastly, plasma concentrations of PAF increase after allergen inhalation in mildly asthmatic subjects. ${ }^{14}$ Therefore, PAF seems to be unique among inflammatory mediators in its ability to cause bronchoconstriction, chemotaxis and activation of eosinophils and neutrophils, ${ }^{23}$ and airway hyperresponsiveness. Not all studies, however, have supported a role for it in causing asthmatic responses. Firstly, inhaled PAF has never been shown to cause a late asthmatic response in human subjects. Secondly, no study has shown that it causes airway hyperresponsiveness in asthmatic subjects when inhaled, ${ }^{24}$ although inhaled allergen has caused airway hyperresponsiveness in asthmatic subjects in many studies. ${ }^{2} 38$ Lastly, some investigators have found that PAF does not induce airway hyperresponsiveness even in non-asthmatic subjects. ${ }^{24}$ Our results also suggest that the factor is not important in causing allergen induced asthmatic responses.

One reason why we found no effect of orally administered WEB 2086 is that sufficient quantities of the antagonist did not reach the appropriate site in the lungs. However, oral WEB 2086, $40 \mathrm{mg}$ administered as a single dose, has previously completely abolished the bronchoconstriction induced by PAF in human subjects. ${ }^{20}$ Therefore, a higher dose, administered three times daily for seven days, is likely to have effectively antagonised the lung receptors in our subjects. Another possible reason for lack of effect of WEB 2086 is subjects' non-compliance in taking the study drugs. We measured plasma concentrations of WEB 2086 during both treatment periods just before allergen inhalation and all subjects had effective concentrations during WEB 2086 treatment and no detectable values during placebo treatment, indicating compliance with taking the study drugs. Lastly, higher local concentrations of WEB 2086 than could be achieved by oral administration may be needed in the airways to antagonise high local concentrations of PAF released during allergen challenge. High local concentrations may be achieved only by inhalation of an antagonist.

In summary, our results show that the oral administration of a potent and selective PAF antagonist at the highest available dose for 
one week does not influence allergen induced asthmatic responses. This study, therefore, does not support a role for PAF as an important mediator in causing the early or late asthmatic responses or the airway hyperresponsiveness after inhaled allergen in asthmatic subjects. However, further studies with an inhaled antagonist to increase availability at the receptor may be warranted.

This study was supported by an operating grant from the Medical Research Council of Canada and from Boehringe Ingelheim. PMO'B is a recipient of a Medical Research Council Scientist award.

1 O'Byrne PM, Dolovich J, Hargreave FE. State of the art: late asthmatic responses. $A m$ Rev Respir Dis 1987;136:740-51.

2 Cockcroft DW, Ruffin RE, Dolovich J, Hargreave FE Allergen-induced increase in non-allergic bronchial reactivity. Clin Allergy 1977;7:503-13.

3 Cartier A, Thomson NC, Frith PA, Roberts R, Hargreave FE. Allergen-induced increase in bronchial responsiveness to histamine: relationship to the late asthmatic response and change in airway caliber. $\mathcal{F}$ Allergy Clin Immunol 1982;70:170-7.

4 Keyzer J, Kauffman HF, de Monchy JG, Keyzer-Udding JJ, de Vries $\mathrm{K}$. Urinary $\mathrm{N}^{\mathrm{T}}$-methylhistamine during early and late allergen-induced bronchial obstructive reaction. f Allergy Clin Immunol 1984;74:240-5.

5 Manning PJ, Rokach J, Malo JL, Ethier D, Cartier A, Girard $\mathrm{Y}$, et al. Urinary leukotriene $\mathrm{E}_{4}$ levels during early and late asthmatic responses. $\mathcal{F}$ Allergy Clin Immunol 1990;86:211-20.

6 Taylor GW, Black P, Turner N, Taylor I, Maltby NH, Fuller RW, et al. Urinary leukotriene $\mathrm{E}_{4}$ after antigen challenge and in acute asthma and allergic rhinitis. Lancet 1989; i:584-7.

7 Beasley RCW, Fetherstone RL, Church MK, Rafferty P, Varley JG, Harris A, et al. Effect of a thromboxane receptor antagonist on $\mathrm{PGD}_{2}$ - and allergen-induced bronchoconstriction. $\mathcal{F}$ Appl Physiol 1989;66:1685-93.

8 Manning PJ, Stevens WH, Cockcroft DW, O'Byrne PM The role of thromboxane in allergen-induced asthmatic responses. Eur Respir f 1991;4:667-72.

9 De Monchy JGR, Kauffman HF, Venge P, Koeter GH Jansen HM, Sluiter HJ, et al. Bronchoalveolar eosinophilia during allergen-induced late asthmatic reaction. Am Rev Respir Dis 1985;131:373-6.

10 Page CP, Archer CB, Paul W, Morley J. PAF-acether: a mediator of inflammation and asthma. Trends Pharmacol Sci 1984;4:239-41.

11 Barnes PJ, Chung KF, Page CP. Platelet activating factor as a mediator of allergic disease. $\mathcal{F}$ Allergy Clin Immunol 1987;81:919-34.

12 Cuss FM, Dixon CMS, Barnes PJ. Effects of inhaled platelet activating factor on pulmonary function and

13 Smith LJ, Rubin AE, Patterson R. Mechanism of platelet activating factor-induced bronchoconstriction in humans. Am Rev Respir Dis 1988;137:1015-9.

14 Chan-Yeung M, Lam S, Chan H, Tse KS, Salari H. The release of platelet activating factor into plasma during allergen-induced bronchoconstriction. $\mathcal{f}$ Allergy Clin Immunol 1991;87:667-73.

15 Casals-Stenzel J, Muacevic G, Weber K-H. Pharmacological actions of WEB 2086, a new specific antagonist of platelet activating factor. 7 Pharmacol Exp Ther 1987;241:974-81.

16 Abraham WM, Stevenson JS, Garrido R. A possible role for PAF in allergen-induced late responses:modification by a selective antagonist. $\mathcal{F}$ Appl Physiol 1989;66: 2351-7.

17 Adamus WS, Heuer HO, Meade CJ, Schilling JC Inhibitory effects of a new PAF acether antagonist WEB 2086 on pharmacologic changes induced by PAF inhalation in human beings. Clin Pharmacol Ther 1990;47:456-62.

18 Johnson PRA, Armour CL, Black JL. The action of platelet activating factor and its antagonism by WEB 2086 on human airways. Eur Respir f 1990;3:55-60.

19 Morris JF, Koski A, Johnson LC. Spirometric standards for healthy nonsmoking adults. Am Rev Respir Dis $1971 ; 103: 57-67$.

20 Cockcroft DW, Murdock KY, Kirby J, Hargreave FE. Prediction of airway responsiveness to allergen from skin sensitivity to allergen and airway responsiveness to histamine. Am Rev Respir Dis 1987;135:264-7.

21 Cockcroft DW, Killian DN, Mellon JJA, Hargreave FE. Bronchial reactivity of inhaled histamine:a method and clinical survey. Clin Allergy 1977;7:235-43.

22 Basran GS, Page CP, Paul W, Morley J. Platelet-activation factor: a possible mediator of the dual response to allergen? Clin Allergy 1984;14:75-9.

23 Chung KF, Barnes PJ. Effects of platelet activating factor on airway caliber, airway responsiveness, and circulating cells in asthmatic subjects. Thorax 1989;44:108-15.

24 Lai CK, Jenkins JR, Polosa R, Holgate ST. Inhaled PAF fails to induce airway hyperresponsiveness to methacholine in normal human subjects. $f$ Appl Physiol 1990;68:919-26. 